\title{
CORRECTION
}

Open Access

\section{Correction to: Relaxing the import proportionality assumption in multi-regional input-output modelling}

Simon Schulte*, Arthur Jakobs and Stefan Pauliuk

The original article can be found online at https://doi.org/10.1186/ s40008-021-00250-8.

\section{*Correspondence:} simon.schulte@indecol.unifreiburg.de Industrial Ecology, University of Freiburg, Tennenbacher Str. 4 79110 Freiburg, Germany

\section{Correction to: Econ Struct (2021) 10:20 \\ https://doi.org/10.1186/s40008-021-00250-8}

The original version of this article unfortunately contained a mistake. The resolution of Figs. 3-7 was low (Schulte et al. 2021).

The correction contains the high-resolution figures (Figs. 3, 4, 5, 6 and 7). author(s) and the source, provide a link to the Creative Commons licence, and indicate if changes were made. The images or other third party material in this article are included in the article's Creative Commons licence, unless indicated otherwise in a credit line to the material. If material is not included in the article's Creative Commons licence and your intended use is not permitted by statutory regulation or exceeds the permitted use, you will need to obtain permission directly from the copyright holder. To view a copy of this licence, visit http:// creativecommons.org/licenses/by/4.0/. 


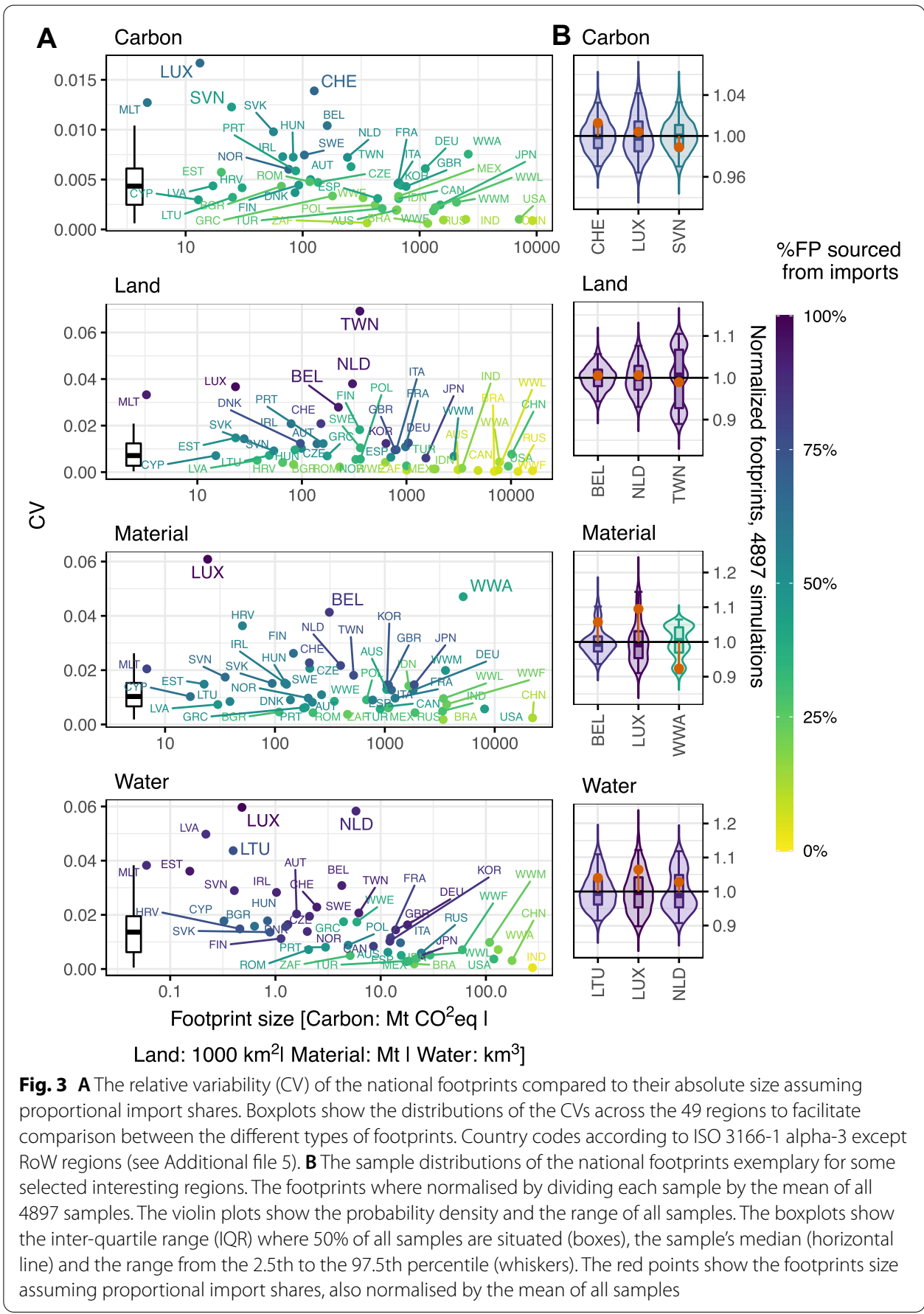




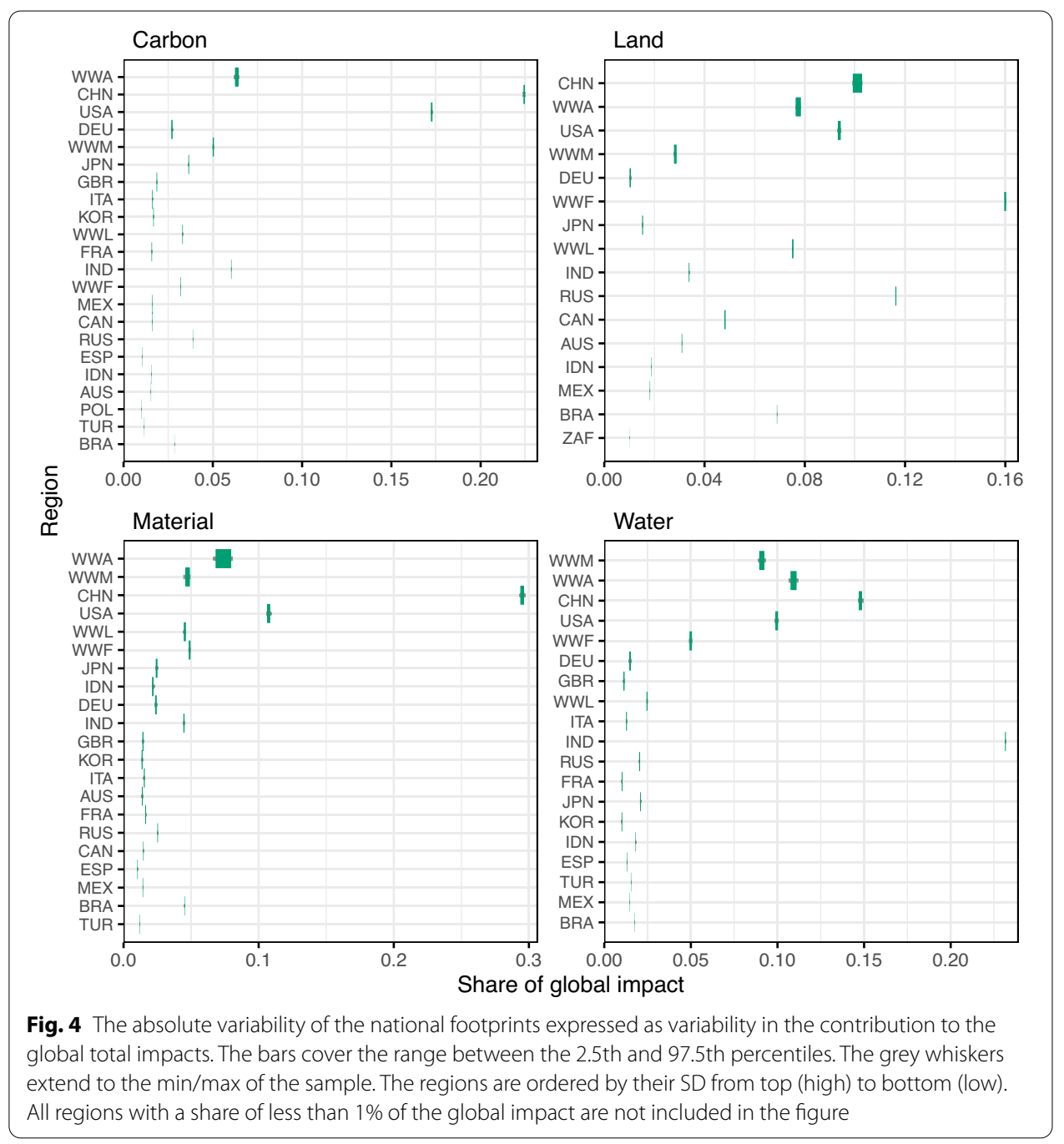




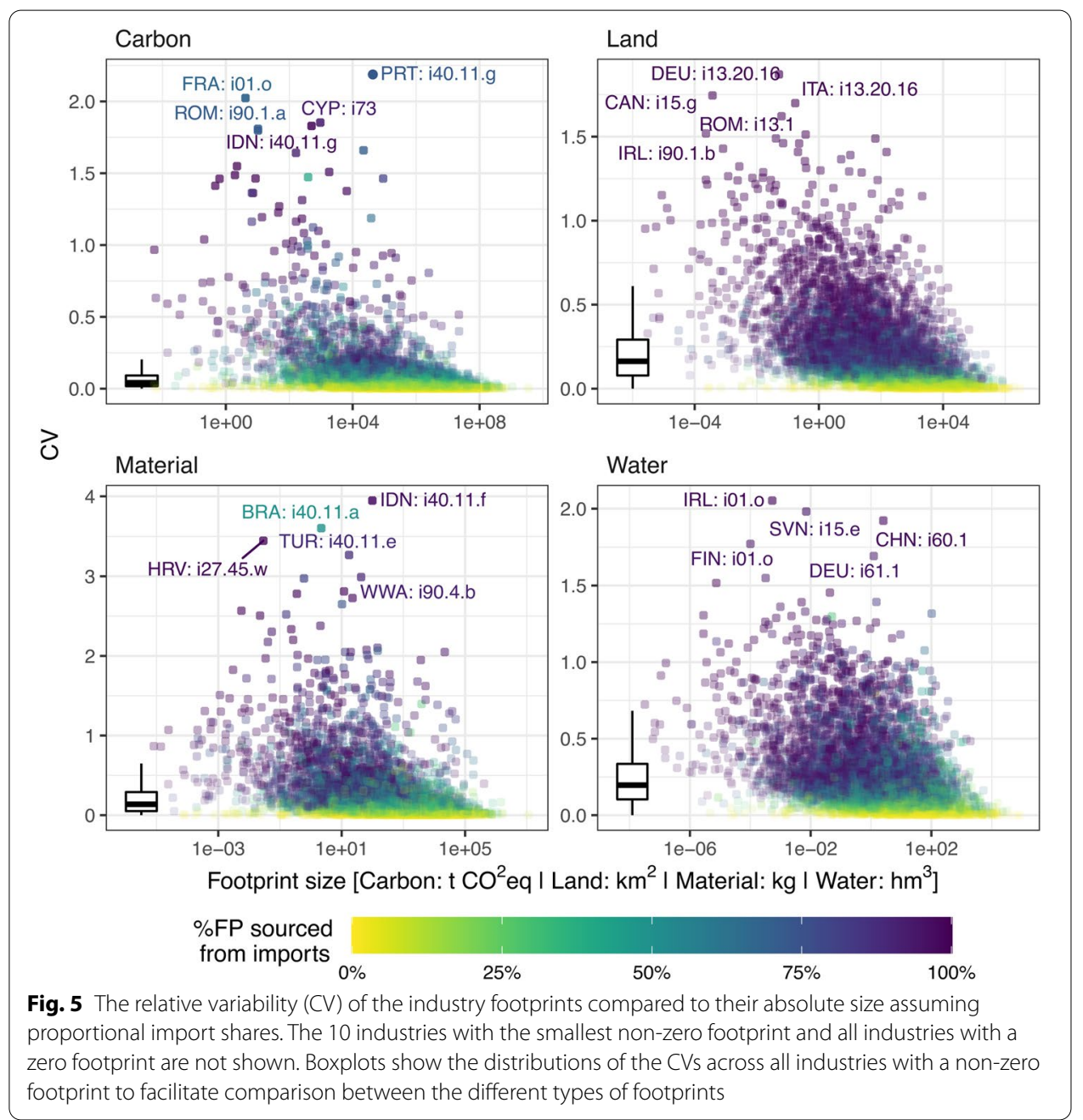




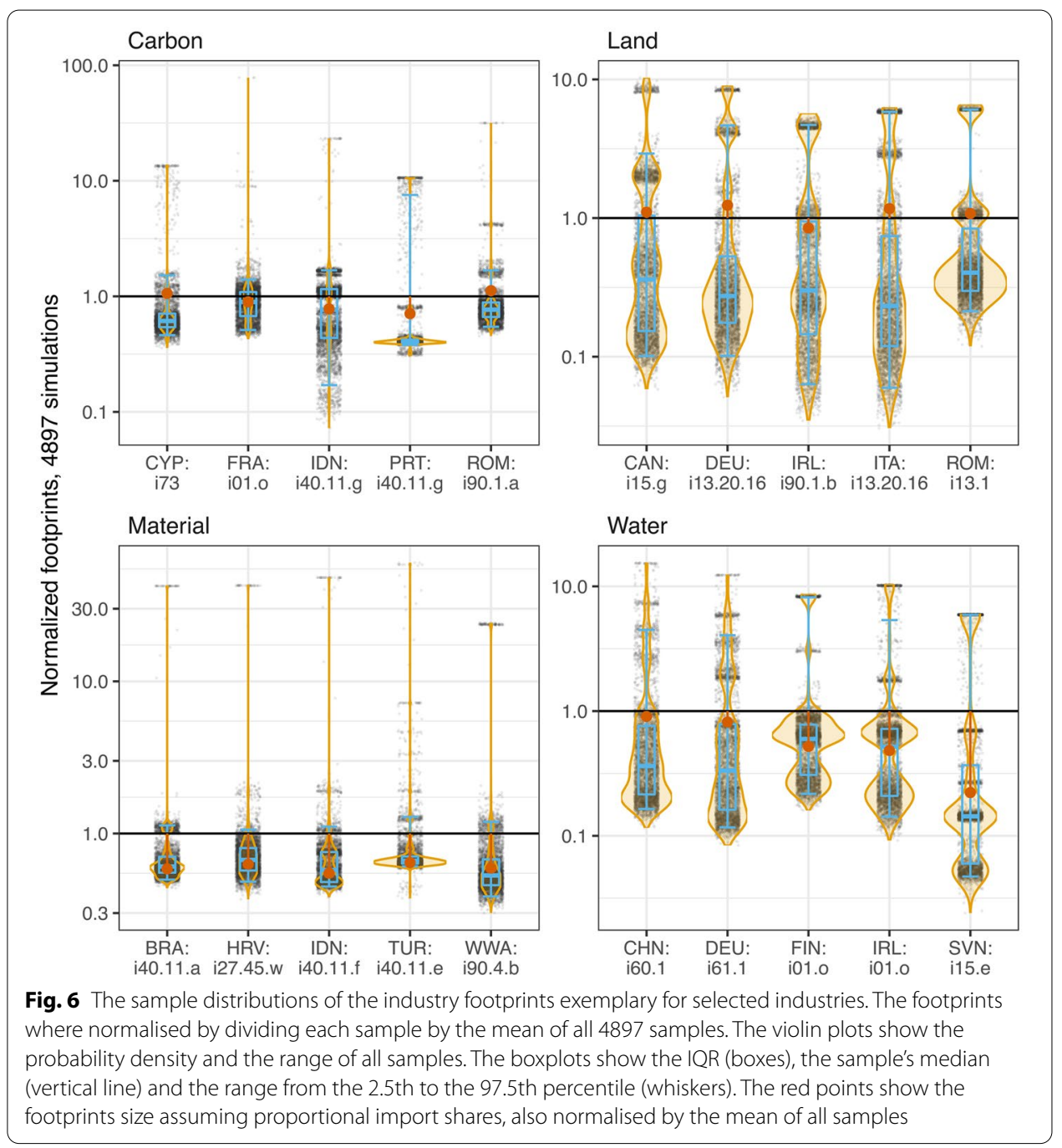




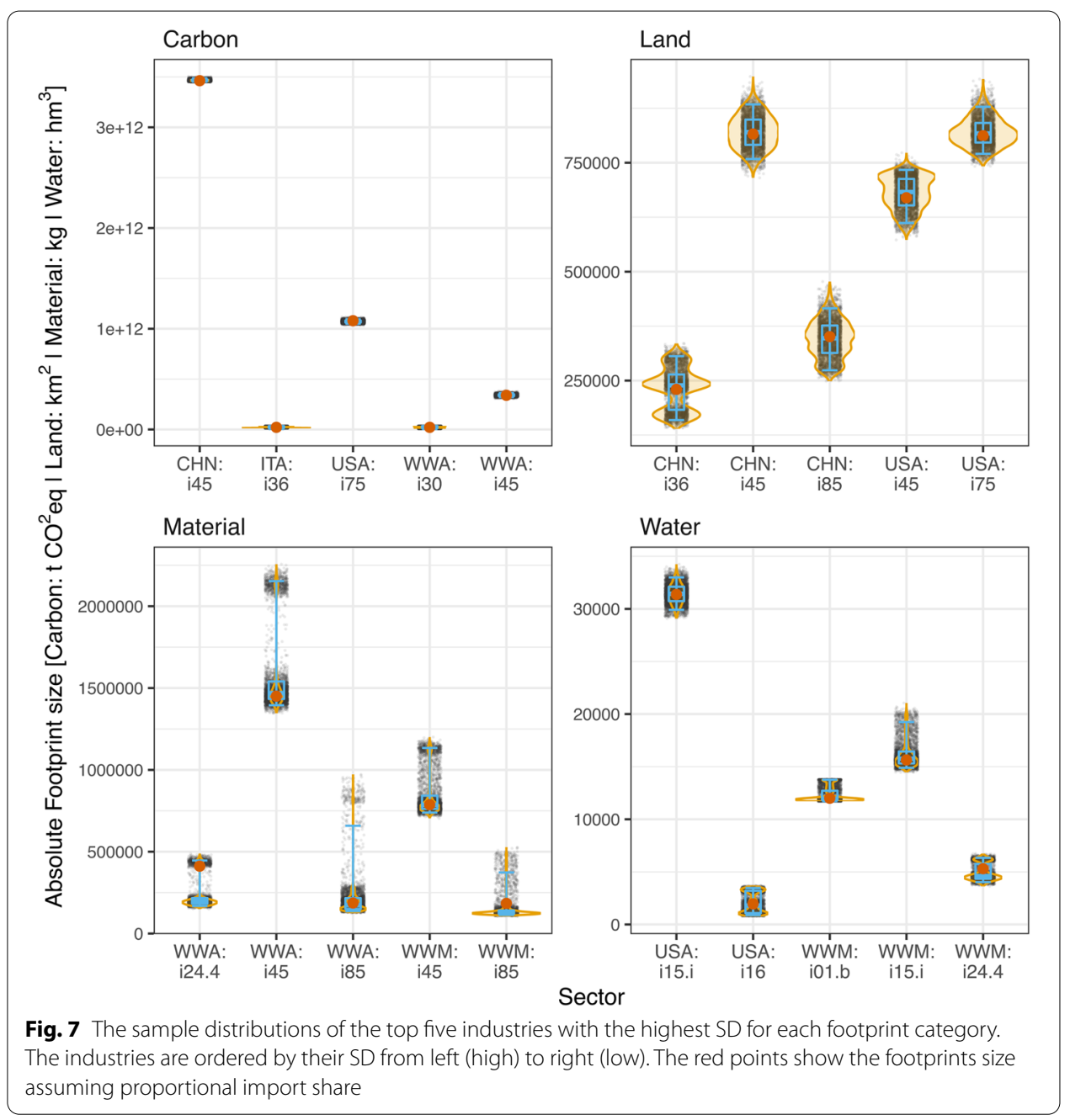

Published online: 17 December 2021

\section{Reference}

Schulte S, Jakobs A, Pauliuk S (2021) Relaxing the import proportionality assumption in multi-regional input-output modelling. Econ Struct 10:20. https://doi.org/10.1186/s40008-021-00250-8

\section{Publisher's Note}

Springer Nature remains neutral with regard to jurisdictional claims in published maps and institutional affiliations. 